\title{
Transition to a Sustainable and Healthy Agri-Food System
}

\subsection{Challenges and Developments}

Agriculture, horticulture, aquaculture, and fisheries are essential for our food production and therefore indispensable in our society. They are an integral part of our economies and cultures. By 2050, the world will have a population of about nine billion, with rapidly changing nutritional needs. With the vast majority of consumers usually opting to pay the lowest price, it prompts the food industry to adopt highly efficient, low-lost production methods. As a consequence, there is little incentive for actors in the food chain to invest in sustainability measures and translate those into cost price. This economic logic leads to a vicious circle.

Current food consumption and production patterns contribute strongly to a number of urgent sustainability challenges in the areas of health and well-being of humans, animals, and the planet. The global food system is under great pressure, due in part to the growing world population and climate change, but also because of how we currently produce and consume food. The Agri \& Food sector has traditionally focused on production and efficiency, producing as much food per square metre as possible at the lowest possible cost and with a limited view of value creation. The predominant focus on productivity, the free market, and profit maximization has shifted social and ecological values and costs to the background. Profit is narrowly defined in monetary terms by externalizing ecological and social costs, which means these 'hidden costs' are usually not reflected in the price of food. A recent estimate puts the 'hidden costs' of global food and land-use systems at $\$ 12$ trillion, which is $20 \%$ more than its market value of $\$ 10$ trillion (Pharo et al. 2019).

These 'hidden costs' can be grouped into two broad categories:

- Planetary/ecological costs: The global food system contributes directly to exceedance of four planetary boundaries: climate change, loss of biodiversity, unsustainable land and water use, and excess nitrogen and phosphorus production (Steffen et al. 2015; IPBES 2019; Willett et al. 2019). Our current global food production and consumption is the single largest greenhouse-gas-emitting sector 
in the world (IPCC 2019). Moreover, the global food system is by far the largest cause of biodiversity loss, terrestrial ecosystem destruction, freshwater consumption, and waterway pollution due to overuse of nitrogen and phosphorus (IPBES 2019; Rockström et al. 2020).

- Societal costs: Globally, more than 820 million people have inadequate access to food, 2 billion people suffer from micronutrient deficiencies (i.e. living on a diet lacking in iron, vitamins, or other micronutrients such as iodine), 600 million people become ill every year from consuming contaminated food causing 420,000 people to die each year, including 125,000 children under the age of 5 year (Havelaar et al. 2015). Another disturbing fact is that the absolute number of undernourished people continues to increase for several years in a row, which makes it very unlikely that the Sustainable Development Goal of Zero Hunger will be accomplished in 2030. The trends of overweight and obesity give additional reason for concern, as they continue to rise in all regions. The most recent data show that obesity is contributing to four million deaths globally and is increasing the risk of morbidity for people in all age groups (FAO, IFAD, UNICEF, WFP, and WHO 2019). Unhealthy dietary patterns lead to an increase in type II diabetes, cardiovascular disease, and some cancers. Six of the eleven disease and mortality risk factors are related to food (Glopan 2016; EAT Lancet 2018).

More and more people are realizing that the current food system will have to be made more sustainable and healthier, but the agricultural sector is lacking in its ability for self-regulation and capacity for governance (Keulartz and Pekelharing 2019). The majority of farmers are stuck in the existing system, and in order to keep their heads above water, many farmers have had to resort to accumulating large debts. They are chained to the banks who fund their businesses and expect farmers to increase their scale and yield. Because of the major pressure put on the system, there is a great deal of disagreement about where to go next within the sector, as witnessed by the massive farmer protests in the Netherlands and other EU countries in 2019, in response to new policies for reducing nitrogen emissions.

Above issues explain why the license to produce for the food sector is under great pressure, while at the same time there is increasing demand for agricultural products. Critical reviews of the agricultural system (e.g. Janssen and Erisman 2016; NewForesight and Commonland 2017; Godfray et al. 2010; SAPEA 2020) warrant a radical transition to a sustainable and healthy agri-food system. The evidence reviewed in the report 'A Sustainable Food System for the European Union' confirms the view that radical system-wide change is required, with 'business as usual' no longer a viable option (SAPEA 2020). There is an urgent need for a new Common Agricultural Policy that goes beyond economic efficiency and maximum production, and also adopts a broader understanding of prosperity. We need an approach that accounts for the climate, nature, animal well-being, public health, and the environment from the outset, rather than requiring retrospective repair legislation (Keulartz and Pekelharing 2019). 
The Netherlands Ministry of Agriculture, Nature and Food Quality has recently developed a new policy for circular agriculture (LNV 2018), with Minister Schouten explaining: 'Farmers want directions, so that's what I'm giving them', in an interview with Trouw newspaper (8 September 2018). However, the question remains whether this new policy will usher in a transition or whether it will simply make minor adjustments and efficiency improvements to the existing system. One of the fundamental questions is to what extent a policy targeted at circular agriculture is compatible with the promotion of free trade in WTO and GATT negotiations and other fora, in particular promoted by the European Union, the USA, and Japan, while at the same time practicing protectionism and subsidies for the domestic agricultural sector (Otero et al. 2013). The European Union's Common Agricultural Policy (CAP) currently accounts for $37.8 \%$ of the total EU budget (Rockström et al. 2020). Rockström et al. (2020) suggest to shift these types of subsidies to reward the production of public goods (such as carbon capture, habitat creation, and improved water quality) for securing the global commons while supporting farming communities.

Within this context, several important trends that may either limit, support, or influence, a transition to a sustainable, healthy and just food system can be identified (in no particular order and non-exhaustive):

- More sustainable purchasing behaviour among consumers: consumer awareness on sustainability is on the rise, although consumer awareness does not translate directly to sustainable purchasing behaviour (Logatscheva 2016). Nevertheless, studies from various continents show that more and more consumers take sustainability into account when buying items (Joshi and Rahman 2017; Heo and Muralidharan 2019; Logatscheva 2019). The Sustainable Food Monitor in the Netherlands notes that consumer spending on sustainable food was 4.9 billion Euro in 2018: an increase of $7 \%$ compared to 2017, while the share of sustainable food in total food expenditure was $11 \%$ in 2018 (Logatscheva 2019). If this trend continues and consumers consistently start buying more sustainable products and adapting their consumption patterns, demand for sustainable agricultural products will increase at the expense of conventional products. For instance, this trend has resulted in larger market shares for organic and biodynamic supermarket chains such as Ekoplaza and Odin in the Netherlands (Distrifood Dynamics 2019). At the same time, this development calls for better methods for measuring sustainability in food chains to ensure transparency for both producers and consumers (see Sect. 6.4).

- Climate change: The boomerang-effect being observed is that the global food system is the single largest greenhouse-gas-emitting sector in the world (IPCC 2019), while climate change will have significant negative impacts on food security (Dawson et al. 2016; IPCC 2019). 'Climate change will affect all four dimensions of food security: food availability, food accessibility, food utilization and food systems stability' (cf. FAO 2016). It will have an impact on human health, livelihood assets, food production and distribution channels, as well as changing purchasing power and market flows (ibid.). People are becoming 
increasingly aware of climate change, and the need to do something about it. Awareness of the causes and impacts of climate change has made society call for a more sustainable and climate-resilient agri-food system.

- Loss of biodiversity: biodiversity is essential for pollination, seed dispersal, climate regulation, pest control, biomass production, nutrient recycling, water recycling, soil formation, and soil retention. As soon as the biodiversity within agricultural systems as well as in ecosystems declines, their resilience diminishes with it. Awareness of the correlation between biodiversity and food production, and related vulnerabilities and opportunities, will help set the transition in motion, particularly with a view to preserving and restoring biodiversity in and around agricultural systems. Nature-inclusive agriculture and regenerative agriculture are important developments in this context (Sect. 6.2).

- Globalization: The global food system has become industrialized and food chains have become longer, more complex, and more international. It runs in parallel with the growing importance, influence, and vested interests of large industrial players, such as seed and feed suppliers, food processing and packaging industry, transport and logistics, and chains of supermarkets and restaurants. As a part of this development, a large part of the markets has been taken over by a small number of companies (WRR 2014). The power of the few is only increasing as a result of globalization and a capitalist economic logic. Consequently, for consumers it is virtually impossible to have an influence on the range of products on offer in supermarkets, while farmers are forced to comply with the demands of a very small group of purchasing organizations. Farmers are increasingly lockedin the system due to increased specialization and investments in one product, one production method, and one market.

Within this context, the Corona-crisis has revealed a number of vulnerabilities to the current global model of unlimited circulation of goods and people. In the short term, the protectionist measures and closure of borders have caused a significant disruption of global agro-food chains, for example, causing a shortage of foreign seasonal workers, destruction of fresh produce due to market failures, or confronting export-dependent farmers with lower prices through their contracts with purchasing companies, wondering whether those contracts are not unilaterally passing the risks on to them. On the medium term, the economic crisis following the Corona-crisis will have major consequences for the global food system for the years to come. It will also provide a window of opportunity for reform and interventions that were first conceived impossible.

- Local food systems: In recent decades, the distance between farmers and citizens has increased, due in part to urbanization, the anonymity of the supply chain, and the increase in scale, which means that consumers hardly know anything about where their food comes from and that farmers no longer feel valued. As a kind of correction mechanism for the economic climate of liberalization, privatization, and globalization, often in combination with environmental concerns, a growing number of food producers and consumers are opting for shorter food chains and local food systems. Examples include food networks, short food chain platforms, citizens' farms, urban farming, and community-based agriculture, in which 
farmers and consumers work together to produce their own food without relying on wholesalers and supermarkets. It enables farmers to receive a fair price for their produce while at the same time restoring the farmer-citizen relationship as well as the relation between humans and nature (see Sect. 6.3).

- Human health: Health is becoming an increasingly important topic in society now that global obesity rates have doubled since the 1980s and other diseases are becoming considerably more prevalent. The number of people with type-2-

diabetes, for instance, has quadrupled over the past 30 years. These developments can mainly be blamed on poor, unhealthy food and diets. People need more information about the origins of food, its nutritional value, its contents, nutrients, and minerals. However, various scandals within the Dutch food industry, such as the fipronil crisis, have left consumers losing confidence in reliable information. In addition, society is becoming more interested in personalized food, food apps, and food blogs, with food gurus such as Jamie Oliver, Nigella Lawson, and Yotam Ottolenghi having tremendous impact on consumers.

- Social justice and poverty: The current food system is not considered fair enough from different perspectives (Alkon and Agyeman 2011). First, equitable access to healthy food is a critical challenge, in particular for lower-income groups (Power 1999; Wertheim-Heck et al. 2019), with more than 820 million people worldwide having inadequate access to food (Havelaar et al. 2015). Second, there are concerns, both within and outside Europe, about wages and working conditions in food chains. 'A condition for the proper functioning of the agricultural system is that the farmers and other agricultural workers who are directly responsible for food production can make a decent living' (cf. NewForesight and Commonland 2017). However, more than three-quarters of smallholder farmers in developing countries are caught up in a poverty trap, which is a trap of low wealth that is virtually impossible to exit because of exclusion from financial markets and an inability to reduce consumption and engage in even a modest savings strategy (Tittonell and Giller 2012). Third, gender inequality and other social inequities are important topics that are often neglected in the analysis and governance of the food system (Schipanski et al. 2016). In general, more attention is required for strategies and conditions that enable a just and fair transformation towards sustainability, in particular related to inclusivity, socio-economic inequities, procedural justice, social and environmental justice, legitimacy, potential winners and losers, and potential trade-offs between social, economic, and ecological interests and values. For instance, evidence suggests there will be winners and losers in reforms to the EU Common Agricultural Policy (CAP) budget and related subsidies (SAPEA 2020; Boulanger and Philippidis 2015; Larrubia Vargas 2017).

- Animal health and welfare: All aspects of animal diseases and well-being of food producing-animals during breeding, rearing, transportation, and slaughter have become increasingly important in recent years. The One Health concept is a worldwide strategy for expanding interdisciplinary collaborations and communications in all aspects of health care for humans, animals, and the environment (Kaplan et al. 2009). The main premise is that if you keep animals 
under healthy conditions, it is also beneficial for people. Visseren-Hamakers (2020) argues that animal health, welfare, and rights should be added as an 18th Sustainable Development Goal (SDG), considering the neglect of animal considerations in discussions on sustainable development.

- Security and conflict: global food system challenges must be viewed from an international perspective and the pursuit of stable geopolitical relations. International trade brings with it mutual dependencies that may contribute to peace, but at the same time climate change, water, and food shortages are major causes of poverty, political instability, conflict and refugeer outflow in many parts of the world (Brauch and Scheffran 2012; Huntjens et al. 2018). A study by the World Food Programme (WFP 2017) found that the greatest refugee outflows are from countries not only experiencing armed conflict but also the highest level of food insecurity (WFP 2017).

Above developments show there is much more to food than only production, kilograms, and certification. Also legitimation, human security, social justice, crossovers with other sectors such as water, energy, IT, healthcare, and well-being, as well as the pursuit of a healthy and sustainable environment have become increasingly important. A societal transformation towards a Natural Social Contract cannot be accomplished without a transition to a sustainable and healthy agri-food system. There is an urgent need for new production strategies and renewable use of raw materials, new revenue models, and innovative entrepreneurship, as well as new forms of governance and management. Strategies that include social justice and equity in the food system, and strategies that increase the use of ecological processes rather than relying on external inputs for crop production, as well as strategies that foster regional food (distribution) networks and waste reduction (see also Schipanski et al. 2016), are considered as Transformative Social-Ecological Innovations (TSEIs) for realizing a transformation towards a Natural Social Contract.

In the following sections several projects of my research group within the context of the food transition are briefly highlighted.

\subsection{NWA Programme 'Transition to a Sustainable Food System'}

Thanks to participation of our research group in the national research programme (NWA) 'Transition to a Sustainable Food System', funded by the Netherlands Organisation for Scientific Research (NWO), we will be able to conduct transdisciplinary research on the governance of the food transition for a period of 3 years (2021-2023). The consortium consists of eight universities and four universities of applied sciences, in close collaboration with actors from civil society, government and private sector. Next to senior capacity, the project includes eight postdoc positions with the universities involved, while participation of early career professionals and students (through BSc and MSc projects) will be supported and facilitated. 
In the Dutch agri-food sector and beyond, many innovative entrepreneurs, citizens, coalitions, and other parties are already actively engaged in the food transition, for example, in realizing short food supply chains (SFSC), communitysupported agriculture (CSA), connecting city and countryside, the protein transition, regenerative, circular and nature-inclusive agriculture (NIL), and true cost accounting (TCA). There is a growing support and need for an integrated approach for specific areas, i.e. integrated area development that connects a number of sustainability challenges from a systemic perspective. This requires collaboration with regionally organized networks that connect to area-specific features such as landscape, biodiversity, cultural identity, and social connections within a region. Specific challenges such as nitrogen deposition and climate challenge also require such an area-oriented and integrated approach. The Dutch Ministry of Agriculture's programme 'Innovation on the farmyard' is also in line with area-oriented working. It is therefore obvious to approach the food transition challenge not only nationally but also regionally, in line with the many inspiring (often bottom-up) sustainability initiatives.

An important starting point of this project is to establish links with professional parties and innovative initiatives from practice. This will result in a collective learning process that is highly transdisciplinary in nature. In doing so, we not only involve the 'new' players and initiatives (niches), but also explicitly make connections with large and existing parties (regime), including food producers and supermarket chains that are part of the Dutch food system. This is to gain insight into how their activities may contribute to, or limit, the transition to a sustainable food system. Many of the technologies and governance approaches that we can use for a sustainable food system are known, but how we can further use these insights for a transition to a sustainable food system is still unclear. We want to provide this clarity through a systemic, transdisciplinary approach. The Netherlands is in a good position to investigate and stimulate the transition towards a sustainable food system.

The overarching goal of this programme is to achieve a better understanding of the Dutch food system (as embedded in an international food system), a new design for a more sustainable future food system, and the identification and validation of steering mechanisms and governance approaches to facilitate the transition to such a food system. The central research question is: what is a sustainable food system and which steering mechanisms and governance approaches can accelerate a transition to a sustainable food system in the Netherlands?

We focus on the following sub-questions (with reference to work packages (WPs)):

1. How can the current Dutch food system be defined and delineated: What are the dynamics and what are the interactions of the current food system in the Netherlands? What are the interfaces between the food system and adjacent systems such as water or energy? (WP1 in collaboration with WP4).

2. How can a future sustainable Dutch food system (with possible subsystems) be defined? What new value systems underlie this; based on what characteristics 
(e.g. on the basis of widely supported sustainability criteria such as the Paris climate agreement, Convention on Biological Diversity, and SDGs) is their success evaluated? (WP2, in collaboration with all WPs).

3. How does the transition challenge take shape in an area-oriented approach? How do the many sustainability initiatives in the Netherlands actually contribute to the transition to a sustainable food system in the Netherlands and abroad? (WP3 in collaboration with WP2, WP4, and WP5).

4. What is the transition challenge from the current to the new system and which governance arrangements can accelerate this transition? Where are opportunities (e.g. business cases, scaling up excellent initiatives), which obstacles must be overcome (e.g. vested interests, perverse incentives such as agricultural subsidies), where are paradigmatic tensions, the winners and losers of transition? (WP5, in collaboration with all other WPs).

\subsection{Nature-Inclusive and Regenerative Agriculture}

Most cropland around the world is characterized by large monocultures, whose productivity is maintained through a strong reliance on costly tillage, external fertilizers, and pesticides (Schipanski et al. 2016). Nature-inclusive agriculture (often also called landscape-inclusive or regenerative agriculture) has the potential to offer a more balanced 'production' of food (such as dairy, meat or vegetables and fruit), biodiversity, water quality, carbon storage, landscape, and other ecosystem services than conventional agriculture. In addition, nature-inclusive agriculture may be more resilient to weather extremes (Erisman et al. 2014; Sanders et al. 2015; Van Doorn et al. 2016) and thus more climate-adaptive. A switch to nature-inclusive does require an extensification and substantial adjustments in business operations (Runhaar et al. 2020) and requires an action perspective for farmers in which a transition to nature-inclusive is feasible, also economically. Many farmers have already taken several measures in recent years for more nature-inclusive management, such as extra grazing, adjustment of fertilization, fitting in field edges or green manure. However, far-reaching integration in business operations is still lacking at most companies (Bouma et al. 2020). In addition to compensation and financial incentives, the motivation of farmers is important: motivated farmers dare to take risks and form their own vision on agriculture. Gaining knowledge and experience with nature-inclusive agriculture can play a major role in this. In addition, researchers see that farmers and other stakeholders need an integrated approach to NIL, circular agriculture, and the underlying themes such as climate, soil, water, and biodiversity (e.g. Cuperus et al. 2019; Spoelstra and van Doorn 2019).

Nature-inclusive agriculture starts with healthy soil, produces food within the boundaries of the natural and social environment and has positive effects on biodiversity and the climate (Erisman et al. 2017). A variety of measure can be deployed, depending on type of farming, biophysical, and geographical context. For crop agriculture measures could include non-inversion tillage, field extensions, green manures, catch crops, all year round green fields, reduction of pesticides, flowering 


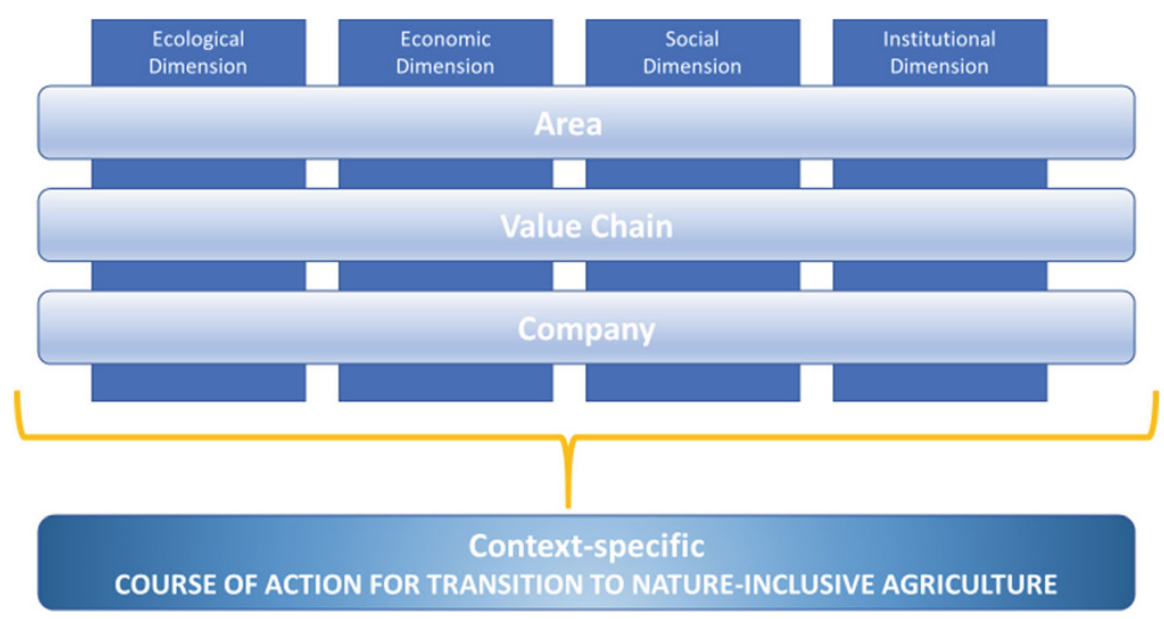

Fig. 6.1 Conceptual model, based on the dimensions of a Natural Social Contract at different levels of scale, for studying a transition towards nature or landscape-inclusive agriculture or circular agriculture

field borders, and landscape elements such as wooded banks and hedges. For dairy farming it could include herb-rich grassland, outdoor grazing, construction of a puddle/wetland system for meadow birds, other cattle breeds in wetland peat areas, fully grass-fed farms, and various landscape elements (for an overview see Erisman et al. 2017).

Nature-inclusive agriculture is not an unambiguous concept, with its origins in the Netherlands, while the term 'regenerative agriculture' is more common in international literature (Rhodes 2017). In general, both concepts entail the inclusion of natural processes into the farming process, while letting nature benefit from the agricultural processes (Degenaar 2019). Since the concept is not yet crystallized, Runhaar et al. (2017) argues "it can be valuable as a "boundary concept", that brings together farmers, stakeholders and policymakers in order to discuss and negotiate shared meanings and objectives that may contribute to agricultural transformation' (see also Velten et al. 2015).

Exploratory research conducted by my research group provides some preliminary but relevant insights on which factors determine the success and/or failure of a transition to nature-inclusive agriculture in The Netherlands. The following conceptual model, based on the dimensions of a Natural Social Contract at different levels of scale, was developed to guide the analysis (see Fig. 6.1). A follow-up study on how to accelerate the transition to nature or landscape-inclusive and circular agriculture in the Netherlands is scheduled in collaboration with a transdisciplinary research consortium in the course of 2021-2023.

Based on the results of this exploratory research, drawing from interviews (in 2019) with various stakeholders working with the concept of nature-inclusive agriculture in practice, the following key findings can be shared here: 
- Ecological dimension: an area-oriented approach (transcending individual or smaller farms) is important, because sustainability gains remain sub-optimal for a limited area of nature-inclusive agriculture, in particular due to (1) nitrogen deposition by adjacent regular farmers (Gies et al. 2019), (2) pesticide or nutrient outflow via surface water, and (3) the minimum required area of natural habitat for specific target species. This does not alter the fact that an individual business approach can already yield substantial sustainability gains, but these can be significantly increased by means of an area-specific approach that is tailored to the specific geographic, ecological, biophysical (including soil type and quality), landscape, social, and cultural context of that area.

- Economic dimension: an area-oriented approach offers more possibilities for a sustainable and profitable business model, through a system of stacked rewards, for the participating farmers. Such a structural reward system for ecosystem services can be set up within a collective or area council in which various stakeholders (including participating farmers, governments, banks, and nature management organizations) are brought together. The ecosystem services (including more biodiversity, better water quality, carbon storage, landscape elements, etc.) supported by the participating farmers can then be rewarded by, for example, an interest discount at the bank, tax reduction at the water board, a surcharge on the milk price, compensations for $\mathrm{CO} 2$ offsets and easier access to land that would otherwise be unable to be used, thanks to the participation of land and nature management organizations. This is illustrated by the case-study 'Land of Values', where an area council was established in which various stakeholders (i.e. governments, private sector, and NGOs) are brought together to allow a system of stacked rewards for the participating farmers.

Transforming the farming process and related business model takes time. At the same time, farmers must be able to earn a living. Ensuring that natural and landscape values thrive may be at odds with conventional agricultural business practices, and it is important that the business has enough time to re-organize. This calls for a sustainable revenue model for the next 10-15 years, taking business risks into account. A revenue model with a mix of rewards and rewarding parties, as used in the 'Land of Values' case study, reduces the dependence on subsidies, and financial risks are mitigated by spreading the risks. In this vein, 'new incentives are needed that reward farmers who minimize their ecological impacts, maximize positive impacts, or who switch to biological pest control or use other types of natural processes' (cf. Runhaar 2017).

- Social Dimension: a collective with an area-oriented approach offers a social context and legitimacy, making it easier for farmers to switch to nature-inclusive agriculture, instead of an individual business approach. This is because social cohesion and shared values among farmers are very strong and determine what they do, while the negative social pressure on farmers who want to do differently is large (Westerink et al. 2019). A collective with multiple farmers and societal stakeholders can simultaneously ensure better social embedding, dialogue, and mutual understanding between farmers and citizens. Another advantage of 
uniting farmers in a collective (in whatever form) is that it provides extra bargaining power in the cooperation and negotiation with other parties.

- Institutional Dimension: an area-oriented approach offers more possibilities for multi-level governance, aiming for a better coherence of measures at different levels, including the business level, at the level of a value chain, at the level of a collective or council for one area (with multiple and divergent stakeholders) and at policy level. Policy instruments and 'positive incentives' (and combinations thereof in so-called 'optimal policy mixes') are essential for the realization of a transition to nature-inclusive agriculture, but this can often only be arranged through optimal coordination between central government, provinces, municipalities and water boards and the strive for an area-oriented and contextspecific approach. Another important aspect is the development of a tangible vision and mission for nature-inclusive agriculture in a specific area. It is important to identify and create shared and common interests and values. Procedural fairness and social inclusion, as well as options for creating added value for all involved, are important. Agreement on these ethical and normative aspects is important to keep actor coalitions together during multi-year and effective collaboration processes.

Our investigations, so far, underscore the importance of governance in the transformation towards nature-inclusive agriculture. 'Governance is about how farmers, companies in agri-food chains, banks, governments, NGOs and other stakeholders interact and try to influence each other in order to achieve their objectives' (cf. Termeer et al. 2013). Based on above research, an important success factor is the effective collaboration in a collective in one area, instead of individual farms that modify their farming processes.

\subsection{Closing the Gaps Between Citizens, Farmers, and Nature}

Recently, interest in local food systems has skyrocketed (Pigford et al. 2018), centred around an approach in which citizens, farmers, and other stakeholders work together to create a sustainable, healthy, and predominantly local food system. Within this context three examples are highlighted:

- Food policy councils (FPCs) as loci for practising food democracy, for example, in Germany (Sieveking 2019), the USA (Scherb et al. 2012; Gupta et al. 2018), and Canada (Sussman and Bassarab 2017).

- Community-supported agriculture (CSA) with its origins in Europe and North America, and similar to the TeiKei system in Japan (Kondoh 2015), and more recently also initiated in China and Singapore. It is a sustainable alternative to industrial agriculture, in which there is direct producer-consumer transaction (White 2020) that allows the producer and consumer to share the risks of farming (Galt 2013). 
- Short Food Supply Chains (SFSC), which 'aim to reconnect the two extremities of the food supply chain, reconcile producers with citizens, stimulate mutual trust and establish a short chain based on common values on food, its origin and production method' (cf. SKIN 2020).

In the Netherlands, more and more citizens want to participate in the transition towards a healthy and sustainable food system (BoerenBusiness 2018). Our research group is currently working to develop a pilot on community food forestry, with the central aim of restoring the natural relation between citizens, food, and nature. A food forest is a multifunctional approach to increase food security and provide ecosystem services (Clark and Nicholas 2013). A well-functioning food forest is actually the most ideal form of circular agriculture, since a healthy ecosystem shows an important basic principle of the Circular Economy: that is, how you organize circularity at the lowest possible level. When combining a food forest with the concept of community-supported agriculture, it provides many opportunities for social cohesion and citizen participation to restore the relationship between citizens, food production, and nature. Community Food Forestry (CFF)/Community AgroForestry (CAF) allows citizens to become co-owner of their own food system. A first pilot is being established by Inholland University in the Netherlands. Other examples that are being studied by our research group include:

Rechtstreex in Rotterdam, an example of short food chains and closer ties between citizens and farmers (see Fig. 6.2), Burgerboerderijen (Citizen Farms Cooperative), and Herenboeren (freehold farms). The aim of the Citizen Farms Cooperative is to reconnect people with the source of their food: 'their' farmers. Establishing direct, local connections between citizens and farmers shortens the distance from grain to bread.

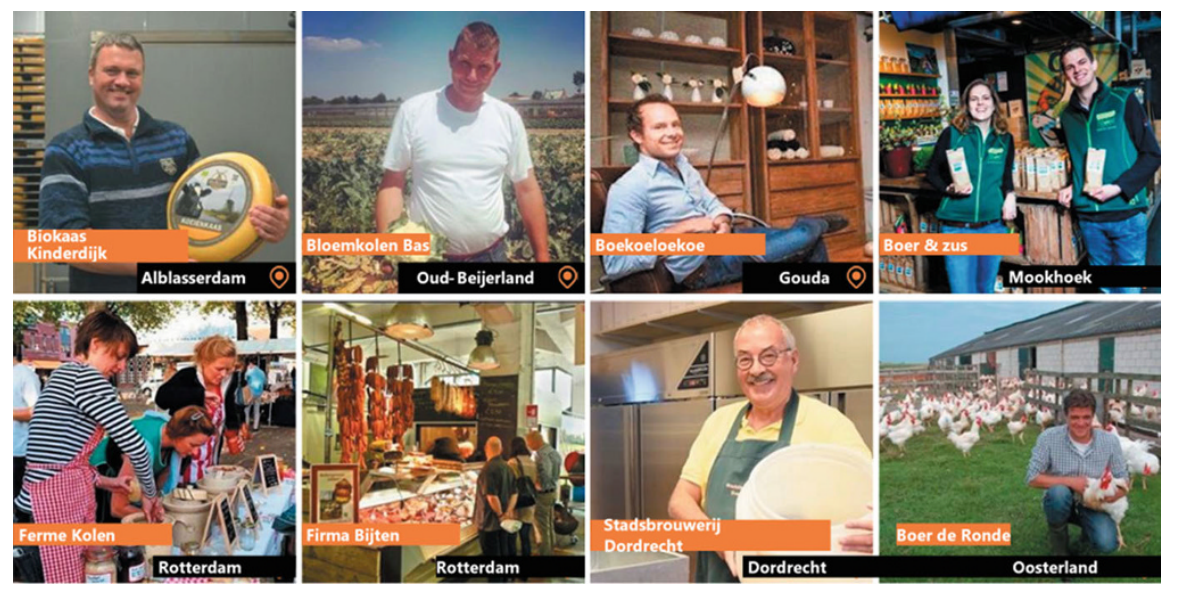

Fig. 6.2 Rechtstreex Rotterdam, an example of the short food chain and closer ties between citizens and farmers (Photocredits: Rechtstreex) 
In general, these projects aim to build a community that coexists with the natural environment and to reconnect people with the source of their food through mutually supportive relationships between farmers and consumers. This has a great deal of positive effects, such as fairer food, no undesirable increases in scale and the shortest possible food chain, without delegating control to supermarkets (Burgerboerderijen 2019). A similar concept is employed by Herenboeren (freehold farms), which are co-owned by groups of consumers who employ demand-driven production practices and consume what they produce (Herenboeren 2019).

\subsection{Measuring Sustainability and Health Aspects of Our Food Chains}

Major changes are visible within our current food system: take a look at the shelves of the average Dutch supermarket and compare them to the situation 15 years ago. A lot has changed, and shelves with sustainable, organic, and ecological brands are getting more common. Quality, taste, production methods, and fair prices for farmers are becoming increasingly important for consumers, and organic and biodynamic supermarket chains such as Ekoplaza and Odin are gaining increasingly large market shares (Distrifood Dynamics 2019). Traditional premium brands and supermarket house brands have stepped up their efforts to give their products a greener, healthier, and fairer image. In some cases this might result in greenwashing, without necessarily leading to more sustainable or healthier products.

In the Netherlands alone, there are almost a hundred quality marks and labels for sustainable, fair, and responsible food. Most of these, however, were developed by businesses themselves, so they are effectively marking their own papers. Coca Cola, for instance, does not hesitate to put a green tick on its bottles, even though they are full of sugar. After all, they claim, it contains no salt, fat, and saturated fat. Perhaps, consumers would benefit more from a smaller number of transparent and independent labels, indicating whether a certain product is animal-friendly, organic, or fair-trade, for instance. These labels must be transparent and reliable, which means they must be subject to strict audits, and quality standards preferably should be laid down in law at the national or European level.

An important challenge is making sustainability and health measurable for consumers, government, and businesses. In the field of healthy food, the nutricode is a promising development, a score that can be used to 'calculate' all the healthy and unhealthy properties of a given foodstuff. These scores can be printed on packaging, to indicate how healthy or unhealthy the product in question is, with A being the healthiest and E the least healthy. This system already exists in France and is currently introduced in Spain and the Netherlands.

My research group is currently working with partners on developing a roadmap for measuring, improving, and communicating sustainability in livestock farming from an integrated perspective. For instance, the carbon footprint is an important indicator for measuring the sustainability of livestock. However, the assessment and labelling of emissions is difficult and a decrease of carbon footprint is often at odds 
with other sustainability criteria such as biodiversity and extensive grazing. There are also other themes of societal importance, such as the relationship between citizen and farmer, animal welfare, landscape, nature, biodiversity, and cultural history. The various aspects of sustainability, and diverse interests, can be found in the various separate quality marks that have been developed. The aim of this project is to form an integral overview of quality marks, measurement methods, and sustainability criteria for livestock farming, consumer perceptions and to provide insight into the areas of tension and diverse interests between them. This information is important to determine the impact that a certain intervention would have on people, animals, and the environment. From the overview, a roadmap is designed for the further development of existing quality marks with regard to criteria, methodology, allocation, in order to match the needs of different target groups, including consumers and business customers. All sectors within meat-producing livestock farming are taken into account.

\subsection{South Holland Food Family: Transition Towards a Sustainable and Self-Sufficient Food System}

The Dutch province of South Holland, with 3.6 million inhabitants living on $3403 \mathrm{~km}^{2}$, is one of the world's most densely populated areas. It includes both Rotterdam, Europe's largest port, and The Hague, the country's second and thirdlargest cities. Remarkably, the province has a large agricultural sector, with arable farming, bulb farming, livestock farming, and even the world's largest contiguous greenhouse area. However, most South Holland food produce is exported-the province's level of self-sufficiency is currently approximately 40\% (Nefs 2017).

The South Holland Food Family (in Dutch: Zuid-Hollandse Voedselfamilie) is an open innovation and food transition network, supported by the provincial government and many partners. The ambition of the Province of South Holland is: 'More sustainable agricultural and food chains, offering healthy, sustainable and affordable food for everyone in the Province of South Holland in five to ten years from now'. Part of this ambition is to achieve a provincial level of $80 \%$ self-sufficiency in 2036. That would save a lot of food miles and yields even fresher products. Moreover, it would strengthen the bond between farmers and citizens, while at the same time, increasing more citizen awareness on the production process itself. But above all, the ambition is to realize a more sustainable food system.

This ambition cannot be achieved through improvement of the current food system. Rather a transition is needed - a fundamental change of the food system's structure, culture, and practice. The Province has adopted a transition approach in its 2016 Innovation Agenda for Sustainable Agriculture. This approach adopts elements from transition management (Loorbach et al. 2017), technological innovation systems (Hekkert and Ossebaard 2010), and a 'Networked Working'-approach (Wielinga and Robijn 2018). Internally, government workers call this combination the 'change approach' and its main goal is to stimulate and facilitate experimentation, innovation, and entrepreneurship within the food transition. 
Organizationally, the transition approach entails: (1) the aforementioned open innovation network for food pioneers and change makers called the South Holland Food Family, (2) a subsidy programme to support experimental projects for a sustainable food system, which has initiated an impressive portfolio of more than 30 experimental projects (in Dutch: Proeftuinen), where food pioneers and change makers show what changes are possible, and (3) a knowledge and development programme to further develop and disseminate knowledge from the experimental projects, making use of reflexive monitoring, impact assessments, and a dynamic learning agenda. The open innovation trajectory followed by the South Holland Food Family is visualized in Fig. 6.3.

The TSEI analytical framework (Sect. 5.1) has been used to analyse institutional change during initiation, development and implementation during the first three years (2015-2018) of the South Holland Food Family innovation network (Huntjens et al. 2020). The framework was used to zoom in on a series or cluster of related action situations (and their context), looking at 'structure' and 'agency', and at the output-outcomes-impact of these action situations (per situation where possible and per series/cluster). A series or cluster of related action situations is referred to as an action arena or transition arena. An important first step in applying the TSEIframework, in this case, was a timeline analysis, because it aims to provide a better insight into a series of action situations and the associated learning history. The timeline method is thus part of the methodology of the TSEI-framework. A total of eight action situations were selected in which we could observe an informal or formal steering of the process (see Table 6.1), based on empirical data from a series of individual interviews with participants of these actions situations, and based on joint reflection on the process during a timeline session with multiple participants. The informal and formal steering and related institutional change that was observed differs per action situation, but usually involves a situation where multiple parties (with different interests, perspectives, and preferences) come together and are confronted with a series of potential actions, where these parties exchange goods and services, try to solve problems, influence each other, learn from each other, and resulting in shared output/outcomes. Table 6.1 provides a brief description of the nature of these action situations and the formal or informal institutional change that occurred.

The example of TSEI-framework application provided here shows when and how local agents change the institutional context itself, which provides relevant insights on institutional work (Beunen and Patterson 2019) and the mutually constitutive nature of structure and agency (e.g. Giddens 1984; Bourdieu 1988, 2005; Seo and Creed 2002). Above institutional analysis also shows the pivotal role of a number of actors, such as network facilitators and provincial deputy, and their capability and skills to combine formal and informal institutional environments and logics and mobilize resources, thereby legitimizing and supporting the change effort. The results are indicative of the importance of institutional structures as both facilitating (i.e., the province's policies) and limiting (e.g. land ownership) transition dynamics. Interestingly, while the provincial government holds some power over such institutions, it also has to operate in wider national and EU- institutional settings 


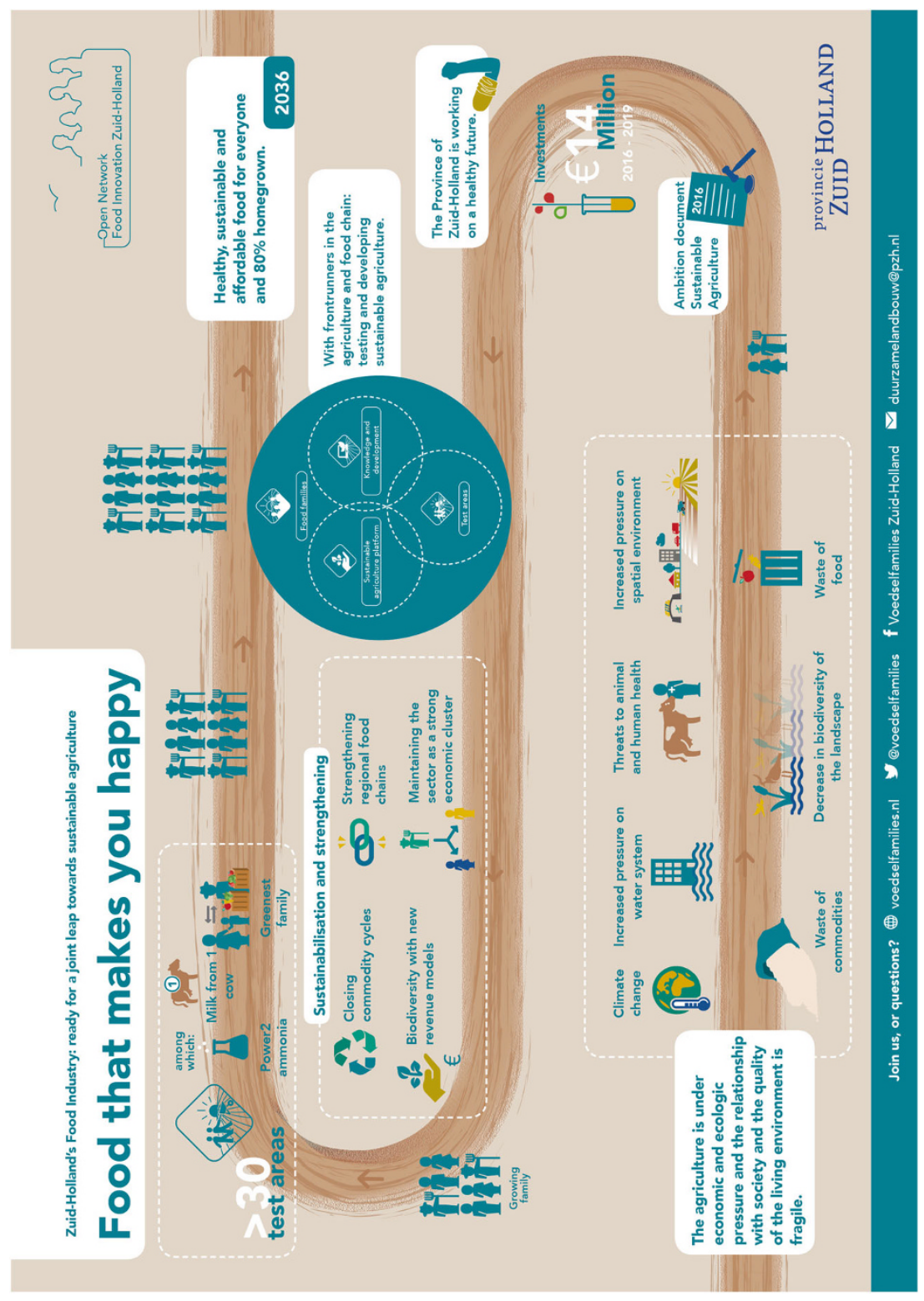

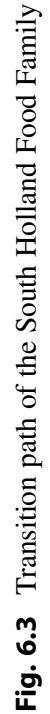




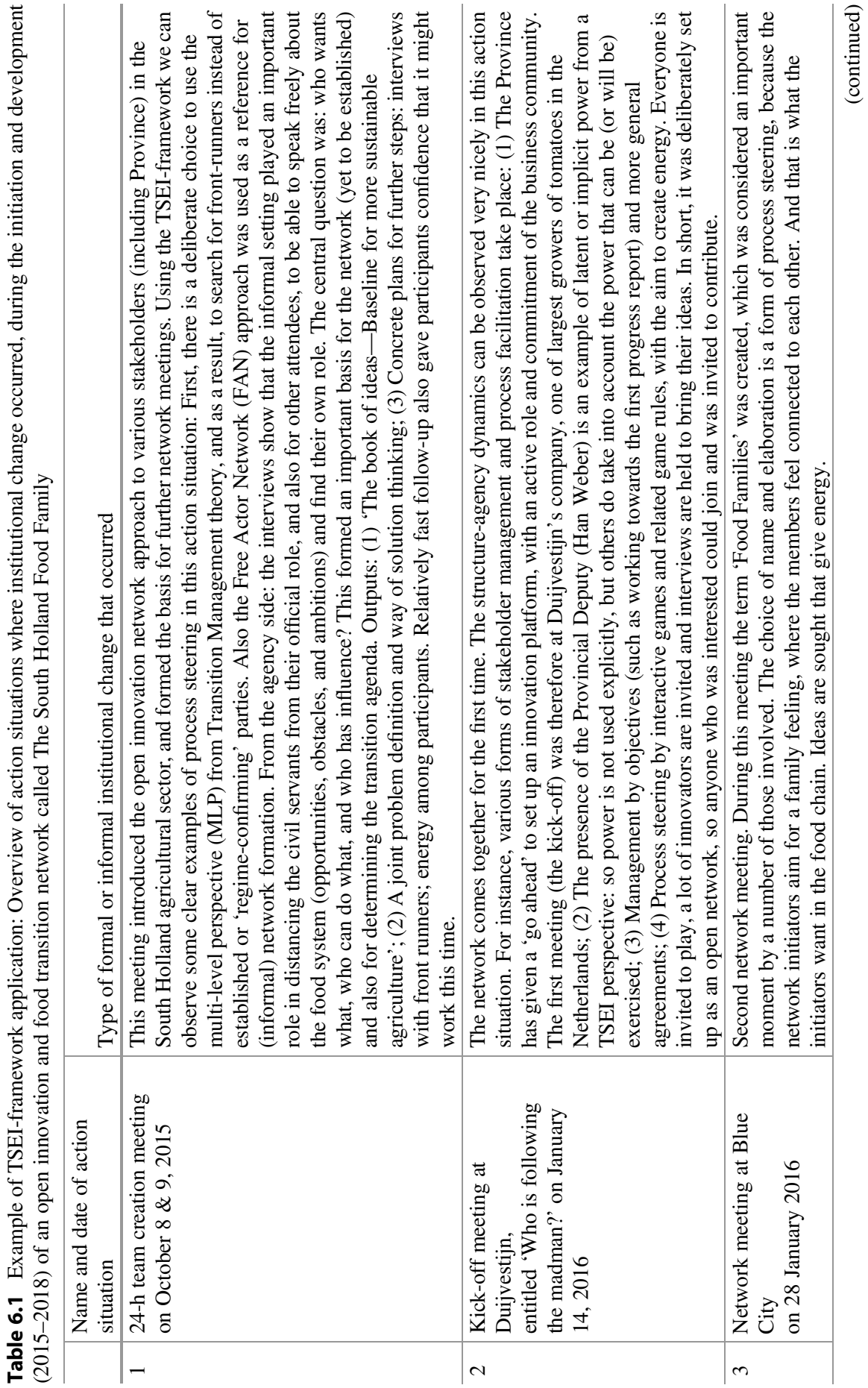




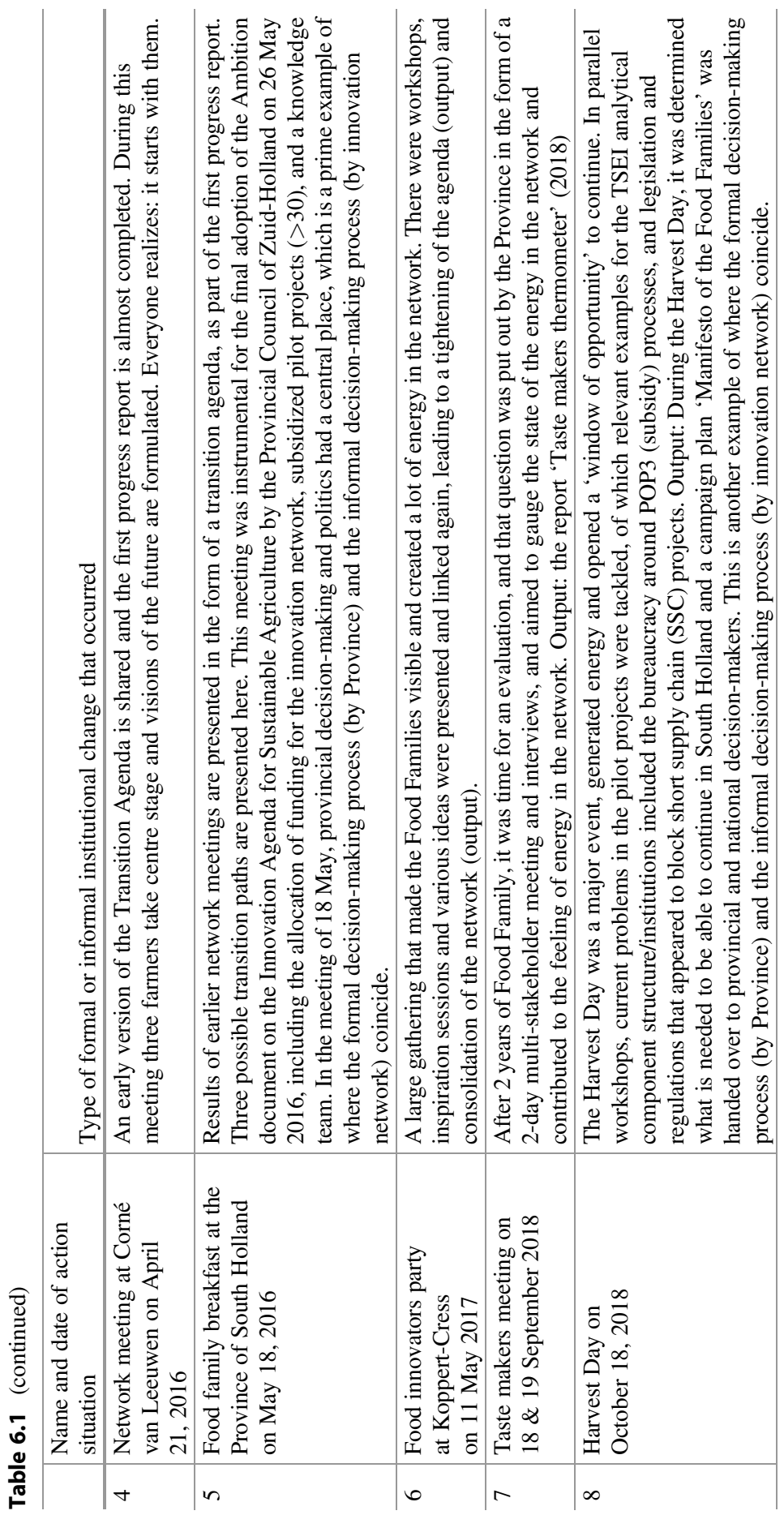


that are beyond its direct influence. This changes the role of the province. Where it started out as an "enlightened incumbent" with an innovation programme, it now is slowly taking on a more 'pioneering' role in its wider institutional environment. Hence, the transition policies reflexively have changed the province's role and identity. More details about the application of the TSEI-framework in this casestudy can be found in a conference paper by Huntjens et al. (2020).

Open Access This chapter is licensed under the terms of the Creative Commons Attribution 4.0 International License (http://creativecommons.org/licenses/by/4.0/), which permits use, sharing, adaptation, distribution and reproduction in any medium or format, as long as you give appropriate credit to the original author(s) and the source, provide a link to the Creative Commons license and indicate if changes were made.

The images or other third party material in this chapter are included in the chapter's Creative Commons license, unless indicated otherwise in a credit line to the material. If material is not included in the chapter's Creative Commons license and your intended use is not permitted by statutory regulation or exceeds the permitted use, you will need to obtain permission directly from the copyright holder.

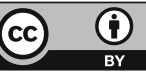

